\title{
Refugee Camp Population Estimates Using Automated Feature Extraction
}

\author{
Brandon Green \\ Department of Geography and Dutton e-Education Institute \\ Pennsylvania State University \\ brandontgreen13@gmail.com \\ Justine I. Blanford \\ Department of Geography and Dutton e-Education Institute \\ Pennsylvania State University \\ jib18@psu.edu
}

\begin{abstract}
Throughout 2018, approximately 68.5 million people were forcibly displaced due to armed conflict, generalized violence, or human rights violations around the world; of those, 40 million were internally displaced persons (IDP), 25.4 million refugees, and 3.1 million asylum-seekers. Effective management of refugee and IDP camps rely on accurate, up-to-date, and comprehensive population estimates. However, obtaining this information is not always easy. Thus, the purpose of this study was to develop a methodology and custom toolset that estimates populations based on $d$ wellings derived from automated feature extraction of high-resolution, multi-spectral orthorectified imagery. Estimates were determined for five Rohingya refugee camp populations and compared with United Nations High Commissioner for Human Rights (UNHCR) baseline data to determine accuracy.
\end{abstract}

Keywords: Pixel-Based, Object-Based, Python, Population Estimate, GIS

\section{Introduction}

Using high resolution aerial or satellite imagery to automate and standardize refugee and internally displaced persons (IDP) population estimates and map camp structures, especially for hard-to-reach areas, can improve humanitarian relief efforts by saving time and money. As of June 2018, the United Nations High Commissioner for Human Rights (UNHCR) estimated approximately 68.5 million people around the world were forcibly displaced due to armed conflict, generalized violence, or human rights violations; of those, 40 million were IDPs, 25.4 million refugees, and 3.1 million asylum-seekers [1]. These people often settle in formal or informal camps, many of which are temporary in nature, where they may receive humanitarian relief and protection [2]. Accurate, up-todate, comprehensive, and quality population data is essential for programming, monitoring, analysis, and advocacy [3]. However, reliable population figures are often not available for a variety of reasons that include challenges in accessing refugee and IDP camps in conflict areas, data bias for political purposes, and the difficult nature of collecting field data during large influxes of persons to a camp [4]. Failure to accurately document the size of camp populations may lead to inadvertent neglect by governments, relief agencies, and humanitarian funding mechanisms, further increasing the suffering of displaced persons [5].

In 2017, the Rohingya refugee crisis in Bangladesh was one of the fastest refugee exoduses in modern times, resulting in the creation of the largest ever refugee camp [6] with approximately 671,000 Rohingya refugees fleeing from Myanmar to Bangladesh in previous years [1]. Refugees have settled in and around existing refugee communities in two main settlements, Kutupalong and Nayapara, overstretching already-limited services and scarce resources [1]. Since the beginning of the crisis, more than 50,000 shelters have been erected, which were built mainly of bamboo, rope, and tarpaulins $[1,7]$.

For the management of refugee or IDP camps, humanitarian relief organizations require up-to-date information about the number of people living in a camp and population changes over time [8]. Population estimates drive funding and advocacy decisions ensuring the displaced have enough food and sufficient supplies for personal hygiene, well-being, and 
household goods [10]. Analyzing population estimates and camp structure geospatial data can determine if a camp is providing not only enough physical protection against the weather but enough space for privacy and dignity [10]. Camp structure data also is used to conduct geospatial analysis, which can ensure shelters are within adequate distances to water sources and other camp services, as well as being located outside risk zones, such as flood and landslide zones [10]. During the initial emergency phase of a refugee crisis, reliable population figures are often not available and asking the refugee or IDP leadership to perform its own census may result in bias information [5]. Fieldbased population estimate approaches are time consuming and often dangerous [9]. Therefore, leveraging aerial and satellite images to derive population estimates is a growing trend within IDP and refugee humanitarian relief missions [10]. Highresolution satellite imagery can be used to map physical structures in refugee and IDP camps, including changes to the number and type of these structures over time. This helps to provide up-to-date population estimates, make available information for hard-to-reach areas, conduct quick assessments during periods of high influx of persons to camps, and assist in planning logistical infrastructure and services such as health care [11].

Manual and automated feature extraction are two methods that can be used to map physical structures in refugee and IDP camps to support population estimates and geospatial analysis [8, 12]. Numerous studies using image-derived refugee and IDP camp population estimates have demonstrated the time, cost, and safety benefits of such methods compared to field-based approaches $[5,8,9,11,13]$. The UNHCR and International Organization for Migration (IOM) are already utilizing remote sensed imagery to update IDP population estimates in Somalia's Afgooye corridor and monitor disaster-induced displacement in Haiti [14].

Both manual and automated approaches require high-resolution imagery to distinguish camp features, which is now increasing in availability, as well as decreasing in cost $[5,11]$. Population estimates can be calculated by multiplying the number of dwellings by the estimated number of people per building, by multiplying the rooftop areas by the estimated average number of people per covered area [13], or by dividing the rooftop area by the estimated average covered area per person [13]. The estimated number of people per building, people per area, or covered area per person can be derived from reports published by governments, humanitarian relief organizations, or utilizing estimates from similar camps [5].
The manual feature extraction approach requires analysts to distinguish features and then manually digitize refugee and IDP camp structures from remote sensed imagery [9]. This approach can yield reasonable precision relative to reference population data (e.g. [5, 8]) of less than 10 to $30 \%$, but it can be problematic in areas where features are dense and layouts are complex resulting in severely overestimating population numbers [5]. Like [5], analysts in [8] and [9] also struggled to distinguish features in complex settings.

The automated feature extraction approach assigns a pixel (pixel-based) or groups of pixels (object-based) to a class based on the relative likelihood of that pixel or group of pixels occurring within each class's probability function [15]. Automated feature extraction can be supervised or unsupervised.

Pixel-based classifiers treat each pixel independent from one another when assigning them to classes [16] However, object-based classifiers compare groups of pixels, or "objects," based on segmentation processes that account for spectral, textural, and spatial properties [17].

Automated feature extraction methods can yield similar results when compared to manual extraction methods [18]. Lastly, unlike the manual approach, automated feature extraction is transferable, can be automated, and is scalable, and thus, more consistent [8].

The development of an automated extraction process requires a high level of remote sensing information and software knowledge, which can be time consuming to acquire and learn [12]. Thus, the purpose of this study is to create a custom Esri ArcMap toolkit and workflow that can be used to automatically calculate population estimates based on feature information derived from an established automated extraction method. This will decrease processing time and enable non-technical users to leverage the benefits of automated extraction to provide humanitarian organizations' access to up-to-date refugee and IDP population estimates and geospatial data depicting camp structures. Thus, ensuring refugee and IDP camps are allocated enough supplies and effectively managed and planned.

\section{Methodology}

2.1 Study Area. For the purpose of this study, the Rohingya refugee crisis was used to develop a custom automated population estimate toolkit. The area of interest is in and around existing refugee communities in two main settlements, Kutupalong and Nayapara (Figure 1). In these areas, several camps have been established. For the purpose of this study, Camps 1E, $1 \mathrm{~W}$ were used to develop the workflow and Camps 17, 
19 and Nayapara RC were further used to evaluate population estimate accuracies.

Figure 1: Kutupalong and Nyapara Refugee Camps in Bangladesh.

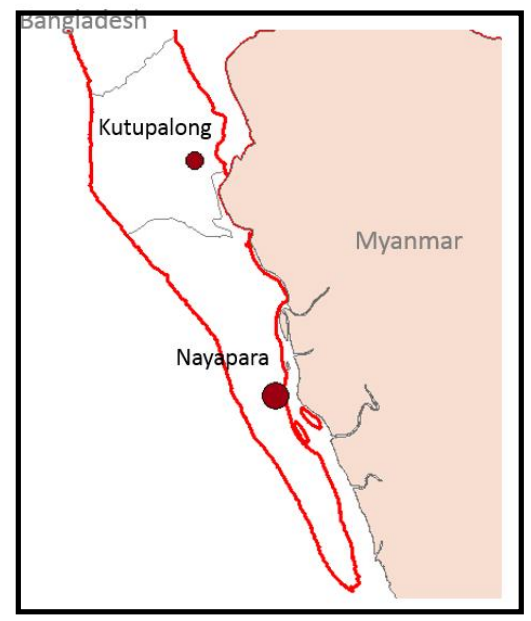

\subsection{Data}

2.2.1 Camp Population Data: Data on Rohingya Refugee Camp populations was obtained from UNHCR and Refugee Relief and Repatriation Commissioner, of the Government of Bangladesh [1921]. The Refugee Relief and Repatriation Commissioner (RRRC) of the Government of Bangladesh, with the support of UNHCR, conduct a shelter-by-shelter refugee count for Rohingya refugee camps in Bangladesh a biweekly bases [20]. The UNHCR publishes periodic reports detailing population, shelter, population density, and average covered area per person calculations with at least a 95\% confidence level and a $10 \%$ margin of error for each camp. In this study data was obtained for April and July 2018, and March 2019 [19-21].

2.2.2 Imagery Data: The United Nations Migration Agency, International Organization for Migration (IOM) collects 10-centimeter resolution, three band (red, green, blue) drone imagery of Rohingya refugee camps every three months. The IOM provides the orthorectified imagery and camp outlines for free through the United Nations Office for the Coordination of Humanitarian Affairs (OCHA) Human Data Exchange (HDX) [22-24]. Imagery captured on July 8, 2018 for Camps 1E and 1W was used to develop the automated feature classification methods (Figure 2). In addition, imagery data for April 2018 and March 2019 were obtained for all camps (1E, 1W, 17,19 and Nayapara RC) and used to determine population estimates in the camp.
Figure 2: Refugee camp image and outline for Camp $1 \mathrm{E}$ and $1 \mathrm{~W}$

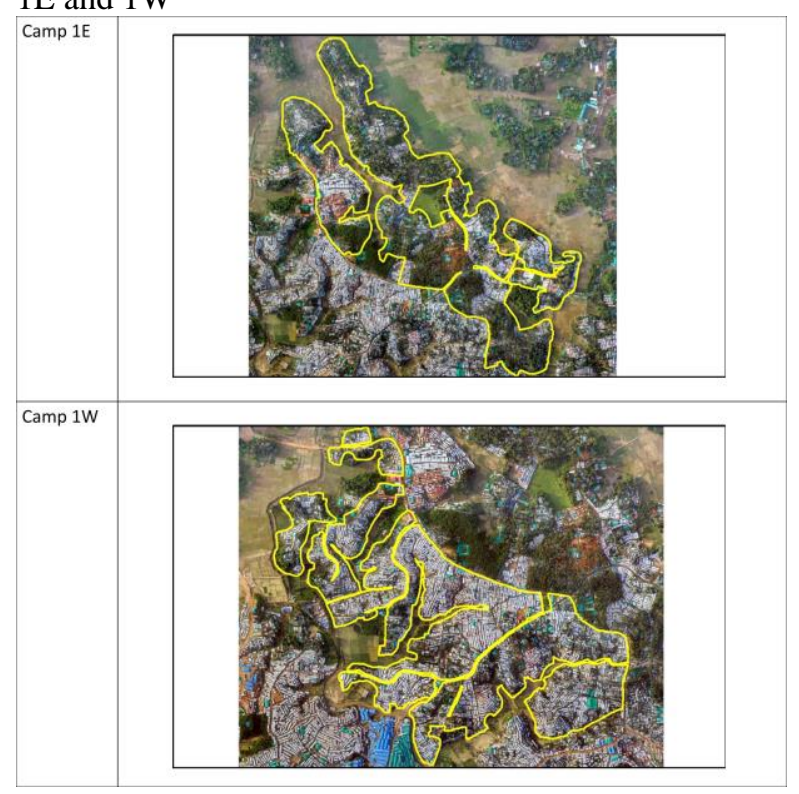

\subsection{Estimating Population Numbers in Refugee Camps}

Population estimates for each of the refugee camps was determined using a number of steps that required (1) identifying building features and then using these features to (2) estimate the camp population based on the total area of the building features and the UNHCR covered area per person statistics (Figure 3) [19-21].

Figure 3: Overview of the object-based method toolkit workflow used to estimate population numbers in refugee camps 


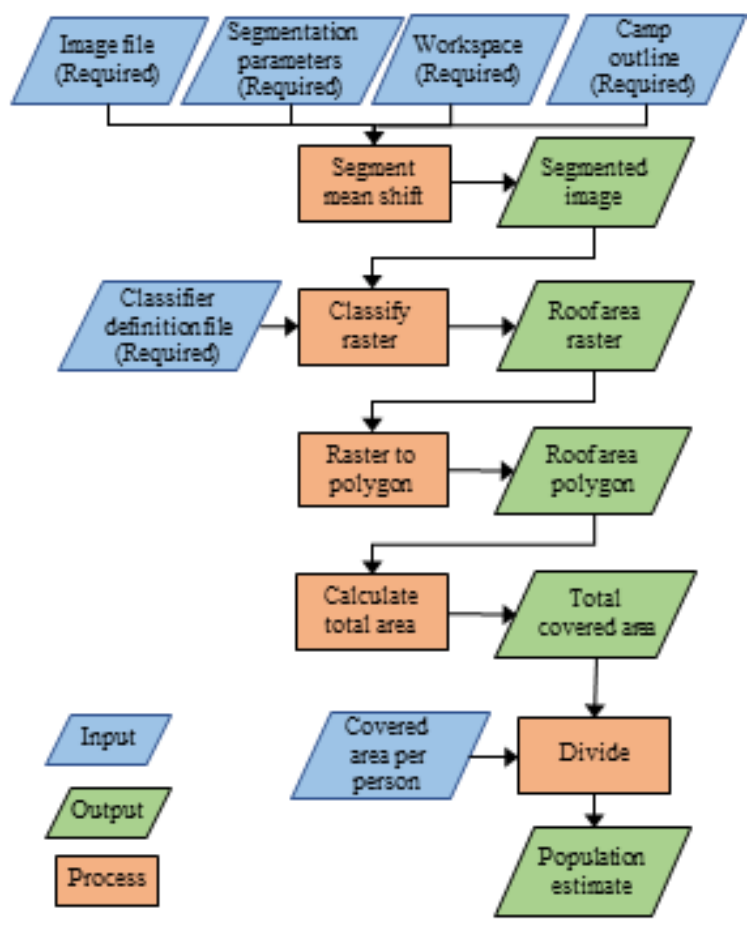

\subsection{Identify Building Features}

Features were identified using a supervised automated featured extraction method as used in several studies $[5,8,17,18]$. Essentially, the supervised classification approach utilizes training areas, groups of pixels, to define each class [15]. For this study, classes for building and non-building features were defined based on a visual inspection of the imagery (e.g. Figure 2). Since roof tops can vary in color, resulting in a wide range of spectral signatures derived from their red, green, blue pixel values, as seen in Figure 2, it was necessary to include training sites that represent each of these features. This ensures the spectral range for each class is discrete enough to accurately assign unclassified pixels to an appropriate class. A generalized roof class would result in a broad spectral range, which non-building spectral signatures may fall within, thus decreasing the accuracy of the classification process. A list of training sites and features descriptions are provided in Table 1. Training areas were manually extracted based on those classes.

Table 1: Training areas and reclassified value

\begin{tabular}{|l|l|l|}
\hline & \multicolumn{1}{|c|}{$\begin{array}{c}\text { Description of } \\
\text { feature }\end{array}$} & $\begin{array}{l}\text { Reclassify } \\
\text { Value }\end{array}$ \\
\hline Building & $\begin{array}{l}\text { Roof comprised of } \\
\text { Feature } \\
\text { orferent colors: white, } \\
\text { blue, gray, and yellow }\end{array}$ & $\begin{array}{l}\text { Covered } \\
\text { area }\end{array}$ \\
\hline Non & Water, dirt and mud, & NoData \\
\hline
\end{tabular}

\begin{tabular}{|l|l|l|}
\hline $\begin{array}{l}\text { building } \\
\text { feature }\end{array}$ & $\begin{array}{l}\text { agriculture and grass, } \\
\text { and trees }\end{array}$ & \\
\hline
\end{tabular}

2.4.1 Segmentation on parameters: Object-based classifiers compare groups of pixels, or "objects," based on segmentation processes that account for spectral, textural, and spatial properties [17]. The spectral, textural, and spatial influence on the segmentation process can be adjusted. Within the Segment Mean Shift Function in ArcMap, larger spectral and spatial detail values (range 0 to 20) will create more discrete groups of pixels by restricting the groupings to small spectral ranges and similar spatial characteristics [25]. Additionally, one can set a minimum segment size, thus preventing the grouping of pixels too small to be the features of interest [25]. An optimal segmentation process should yield objects that correlate to the features of interest as identified in each class. This study compared the three segmentation parameter combinations identified in Table 2 and determined through a visual inspection that combinations 2 and 3 yielded the best results. The larger spectral and spatial detail value segmentation combinations produced better results because the similar spectral signatures of some roof types and nonroof features, such as brown roofs and dirt and mud, required more discrete groups of pixels to differentiate those features from one another.

Table 2: Description of spectral and spatial detail of each segmentation

\begin{tabular}{|l|c|c|c|}
\hline $\begin{array}{l}\text { Segmentation } \\
\text { Name }\end{array}$ & $\begin{array}{c}\text { Spectral } \\
\text { Detail }\end{array}$ & $\begin{array}{c}\text { Spatial } \\
\text { Detail }\end{array}$ & $\begin{array}{c}\text { Minimum } \\
\text { Segment } \\
\text { Size in } \\
\text { Pixels }\end{array}$ \\
\hline Seg1 & 15.5 & 15 & 20 \\
\hline Seg2 & 18 & 17 & 20 \\
\hline Seg3 & 18 & 17 & 200 \\
\hline Image & - & - & - \\
\hline
\end{tabular}

2.4.2 Classification Process: During classification, unclassified pixels or objects were assigned a class based on the relative likelihood of that pixel or object occurring within each class's probability density function [15]. Multiple methods are available to determine the relative likelihood of a pixel and include maximum likelihood (MLC), random forest (RF), and support vector machine (SVM). Each of these methods was assessed, and it was determined that MLC yielded the best results.

To assess which method was best for identifying objects in the imagery, the kappa coefficient and overall, user, and producer accuracies for each of the parameter settings for the MLC, RF, and SVM 
methods was calculated (Table 3). The accuracies were calculated by using 110 test points for each class, except for the yellow roof class, which only used 40, due to the limited number of that feature, to compare the original and classified images. The kappa coefficient is a measure of agreement between the original image and classification results and determines if the errors are significantly better than random [26]. The user accuracy identifies the percentage of test points for each class that corresponds to the ground truth [16]. The producer accuracy identifies the percentage of test points for each class that were correctly assigned to each class [16].

Table 3: Training Classifier methods and parameter settings

\begin{tabular}{|l|c|c|c|}
\hline Image & $\begin{array}{c}\text { MLC } \\
\text { Seg2, Seg3, } \\
\text { Image }\end{array}$ & $\begin{array}{c}\text { SVM } \\
\text { Seg, Seg3, } \\
\text { Image }\end{array}$ & $\begin{array}{c}\text { RF } \\
\text { Seg2, } \\
\text { Seg3, } \\
\text { Image }\end{array}$ \\
\hline $\begin{array}{l}\text { Segment } \\
\text { Attributes }\end{array}$ & $\begin{array}{l}\text { Color, mean; } \\
\text { Color, mean, } \\
\text { rectangularity }\end{array}$ & $\begin{array}{l}\text { Color, mean; } \\
\text { Color, mean, } \\
\text { rectangularity }\end{array}$ & $\begin{array}{c}\text { Color, } \\
\text { mean }\end{array}$ \\
\hline $\begin{array}{l}\text { Max No } \\
\text { Samples } \\
\text { per Class }\end{array}$ & NA & 500 & 1000 \\
\hline $\begin{array}{l}\text { Max No } \\
\text { Trees }\end{array}$ & NA & NA & 50 \\
\hline $\begin{array}{l}\text { Max Tree } \\
\text { Depth }\end{array}$ & NA & NA & 30 \\
\hline
\end{tabular}

The training areas (Table 1) were used to train the MLC, RT, and SVM classifiers using parameters listed in Table 3 for both the segmented (seg2 and seg3) (object-based) and original test (pixel-based) images. The resulting classifier definition files were then used to classify features in the images and assessed for accuracy in classifying each of the different roof types and non-building features (Table $1)$.

For features with the same spectral signature as non-covered items (Table 1), misclassifications occurred. This included brown and dark-tone roofs, which were misclassified as dirt or mud and vice-versa (Table 4). Additionally, water, dirt and mud, and agriculture and grass were misclassified as one another; however, this was deemed insignificant for this study, as those classes would not affect the roof area calculation (Table 4). It was determined that the MLC method using Seg2 as the input raster and the color, mean, and rectangularity segment attributes yielded the best results with an overall accuracy of $94 \%$ and kappa coefficient of 0.87 in classifying building features (Table 5).
Table 4: Classification accuracy assessments for each class - MLC, Seg2, Color, mean, and rectangularity method

\begin{tabular}{|l|l|l|}
\hline Class & $\begin{array}{l}\text { Producer } \\
\text { Accuracy }\end{array}$ & $\begin{array}{l}\text { User } \\
\text { Accuracy }\end{array}$ \\
\hline Light-tone roof & 87.96 & 92.23 \\
\hline Orange roof & 98.18 & 97.30 \\
\hline Green roof & 97.27 & 100.00 \\
\hline Brown roof & 47.27 & 92.86 \\
\hline Blue roof & 97.27 & 94.69 \\
\hline Dark-tone roof & 81.65 & 72.36 \\
\hline Yellow roof & 90.00 & 94.74 \\
\hline Water & 80.77 & 32.94 \\
\hline Dirt and mud & 57.80 & 84.00 \\
\hline Agriculture and grass & 10.91 & 24.00 \\
\hline Trees & 52.34 & 58.33 \\
\hline
\end{tabular}

Table 5: Classification accuracy assessments for building and non-building features - MLC, Seg2, Color, mean, and rectangularity method

\begin{tabular}{|l|l|l|}
\hline Class & $\begin{array}{l}\text { Producer } \\
\text { Accuracy }\end{array}$ & $\begin{array}{l}\text { User } \\
\text { Accuracy }\end{array}$ \\
\hline Building & 91.82 & 98.31 \\
\hline Non-building & 97.44 & 88.03 \\
\hline
\end{tabular}

\subsection{Population Analysis}

Once image object features were identified, the area of each rooftop was determined. Since multiple rooftop classes were identified based on different colors, these were reclassified to represent a single feature type (covered area, Table 1). The reclassified image was converted to a polygon, and the total rooftop area was determined. Total population for each camp was then estimated by dividing the total covered area by the average covered area per person, which should be at a minimum of 3.5-square-meters per person but can range to 4.5-square-meters in harsh environments [27]. The minimum space ensures people have sufficient covered space to provide protection from the climate and provide enough space for fresh air, security, privacy and health [27]. In reality, the average covered area per person may vary from camp to camp, and therefore, the values for each camp were obtained from UNHCR Rohingya Refugee census reporting (Table 6) and used to determine population. However, if fieldbased population reports do not exist, one can use the UNHCR recommended figures to obtain a rough population estimate [27].

Table 6: April 2018 covered area (square-meter) per person estimates 


\begin{tabular}{|l|l|}
\hline Camp & $\begin{array}{l}\text { Covered-area } \\
\text { per person [20] }\end{array}$ \\
\hline $1 \mathrm{E}$ & 3.69 \\
\hline $1 \mathrm{~W}$ & 4.77 \\
\hline 17 & 3.55 \\
\hline 19 & 3.85 \\
\hline Nayapara RC & 2 \\
\hline
\end{tabular}

\subsection{Accuracy assessment}

Accuracy of population estimates were determined by comparing the population estimates with those recorded for each camp [19-21]. The percent margin of error and root mean square error (RMSE) were calculated. The percent margin of error measures the percent difference between the tool estimates and UNHCR baseline data. The RMSE is the standard deviation of the difference between the tool estimates and baseline data. Additionally, the kappa coefficient and overall, user, and producer accuracies were calculated to determine the level of misclassification within a $10 \%$ area of each camp classification using 110 test points for each class.

2.7 Automating the process: developing the toolkit To automate the process, a custom toolkit was developed using ArcPy and loaded into a custom toolbox created in ArcMap. The parameters required for the toolkit are summarized in Table 7 and outlined in Figure 3.

Table 7: Custom toolkit user parameters

\begin{tabular}{|l|l|l|}
\hline $\begin{array}{l}\text { Toolkit } \\
\text { parameter }\end{array}$ & $\begin{array}{l}\text { Data } \\
\text { Type }\end{array}$ & Note \\
\hline $\begin{array}{l}\text { Camp name } \\
\text { (required) }\end{array}$ & String & $\begin{array}{l}\text { Used for output } \\
\text { naming convention } \\
\text { and final report }\end{array}$ \\
\hline $\begin{array}{l}\text { Image date } \\
\text { (required) }\end{array}$ & String & $\begin{array}{l}\text { Used for output } \\
\text { naming convention } \\
\text { and final report }\end{array}$ \\
\hline $\begin{array}{l}\text { Image file } \\
\text { (required) }\end{array}$ & $\begin{array}{l}\text { Raster } \\
\text { Layer }\end{array}$ & $\begin{array}{l}\text { Imagery must } \\
\text { correlate with } \\
\text { classifier definition } \\
\text { file. }\end{array}$ \\
\hline $\begin{array}{l}\text { Classification } \\
\text { method } \\
\text { (required) }\end{array}$ & String & $\begin{array}{l}\text { Default object-based } \\
\text { method }\end{array}$ \\
\hline $\begin{array}{l}\text { Classifier } \\
\text { definition file } \\
\text { (required) }\end{array}$ & FCD & $\begin{array}{l}\text { Classifier definition } \\
\text { file must correlate } \\
\text { with imagery. }\end{array}$ \\
\hline $\begin{array}{l}\text { Covered area } \\
\text { per person } \\
\text { (required) }\end{array}$ & Double & $\begin{array}{l}\text { Based on average } \\
\text { covered area (sqm) per } \\
\text { person. Default 3.5 } \\
\text { [27] }\end{array}$ \\
\hline
\end{tabular}

\begin{tabular}{|l|l|l|}
\hline $\begin{array}{l}\text { Workspace } \\
\text { (required) }\end{array}$ & Folder & Output location \\
\hline $\begin{array}{l}\text { Spectral } \\
\text { Detail }\end{array}$ & Double & $\begin{array}{l}\text { Default parameters are } \\
\text { provided. }\end{array}$ \\
\hline Spatial Detail & Double & $\begin{array}{l}\text { Default parameters are } \\
\text { provided. }\end{array}$ \\
\hline $\begin{array}{l}\text { Minimum } \\
\text { Segment Size } \\
\text { in Pixels }\end{array}$ & Double & $\begin{array}{l}\text { Default parameters are } \\
\text { provided. }\end{array}$ \\
\hline Camp outline & $\begin{array}{l}\text { Feature } \\
\text { class }\end{array}$ & $\begin{array}{l}\text { Used to create a raster } \\
\text { mask (Decrease } \\
\text { processing time) }\end{array}$ \\
\hline
\end{tabular}

\section{Results}

Population estimates were evaluated for five Rohingya refugee camps, that include Camps $1 \mathrm{E}$ and $1 \mathrm{~W}, 17,19$ and Nayapara RC using imagery collected in April and July 2018 and March 2019 [22-24]. The size of each of these camps varied (Figure 4) ranging from 10,000 to 40,000 people.

Figure 4: Population of each refugee camp during April and July 2018, and March 2019.

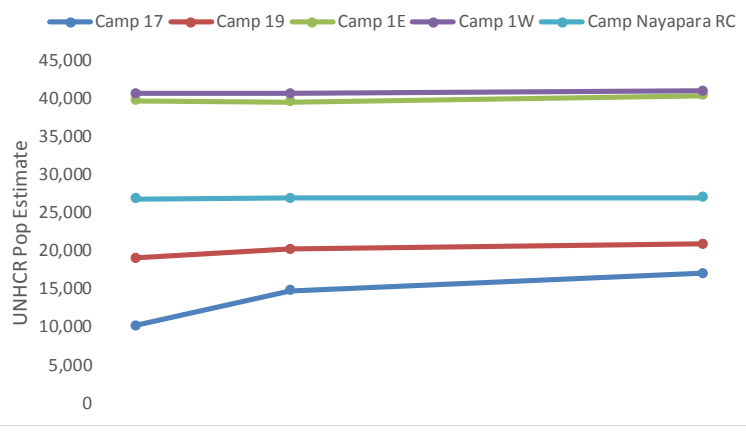

The average number of covered area (squaremeter) per person ranged between 2 and 4.7 with three camps falling within the minimum space requirement of 3.5 and 4.5 square-meters per person (Table 6) [27].

Three tests were conducted for each camp and image date. The first test was a pixel-based classification method using the MLC classifier definition file derived from the July 2018 test image and training areas. The other two were object-based methods, one using the same classifier definition file as the pixel-based method and the other using a MLC definition file derived from the seg2 segmentation raster with the color, mean, and rectangularity segment attributes. The values of $15.5,15$, and 20 were used as the spectral, spatial detail, and minimum segment size parameters for the two object-based methods based on visual inspection of multiple combinations. The UNHCR stopped reporting average covered area per person information after April 2018 (Table 6), 
therefore this study was limited to those figures to calculate population estimates beyond April 2018. Of the three tests, MLC Sep2 method yielded the best results (Table $8,9,10$ ).

Table 8: Tool population estimates and accuracy assessment. Object-based method using seg2 MLC classifier definition file.

\begin{tabular}{|l|l|l|c|c|}
\hline Camp & $\begin{array}{l}\text { UNHCR } \\
\text { Population } \\
\text { Estimates } \\
\text { (Apr'18, Jul } \\
\text { '18, Mar'19) } \\
\text { [20, 21, 22] }\end{array}$ & $\begin{array}{l}\text { Tool } \\
\text { Population } \\
\text { Estimate } \\
\text { (Apr'18, } \\
\text { Jul '18, } \\
\text { Mar'19) }\end{array}$ & RMSE & $\begin{array}{l}\text { Percent } \\
\text { margin } \\
\text { of } \\
\text { error }\end{array}$ \\
\hline $1 \mathrm{E}$ & 39,724 & 44,002 & 13,472 & 25.6 \\
& 39,608 & 38,023 & & \\
& 40,436 & 58,936 & & \\
\hline $1 \mathrm{~W}$ & 40,658 & 39,215 & 5,880 & 5.3 \\
& 40,658 & 43,482 & & \\
& 40,964 & 31,288 & & \\
\hline 17 & 10,092 & 36,226 & 31,066 & 340.8 \\
& 14,669 & 44,617 & & \\
\hline 19 & 16,935 & 53,205 & & \\
\hline Nayapara & 18,982 & 32,637 & 18,077 & 117.1 \\
RC & 20,149 & 40,194 & & \\
\hline & 26,820 & 40,621 & & \\
\hline
\end{tabular}

Table 9: Classification accuracies for building and non-building features. Object-based method using seg2 MLC classifier definition file.

\begin{tabular}{|l|l|l|l|l|}
\hline Camp & $\begin{array}{l}\text { Mean } \\
\text { Producer } \\
\text { Accuracy } \\
\text { - Building } \\
\text { Features } \\
\text { (Apr'18, } \\
\text { Jul '18, } \\
\text { Mar '19) }\end{array}$ & $\begin{array}{l}\text { Mean } \\
\text { Accuracy } \\
\text { - Building } \\
\text { Features } \\
\text { (Apr'18, } \\
\text { Jul '18, } \\
\text { Mar '19) }\end{array}$ & $\begin{array}{l}\text { Mean } \\
\text { Producer } \\
\text { Accuracy } \\
\text { - Non - } \\
\text { Building } \\
\text { Features } \\
\text { (Apr'18, } \\
\text { Jul '18, } \\
\text { Mar '19) }\end{array}$ & $\begin{array}{l}\text { Mean } \\
\text { User } \\
\text { Accuracy } \\
\text { - Non - } \\
\text { Building } \\
\text { Features } \\
\text { (Apr'18, } \\
\text { Jul '18, } \\
\text { Mar'19) }\end{array}$ \\
\hline 1E & 85.64 & 93.00 & 89.52 & 79.67 \\
\hline $1 \mathrm{~W}$ & 83.67 & 95.42 & 93.24 & 78.41 \\
\hline 17 & 89.05 & 97.94 & 96.21 & 81.22 \\
\hline 19 & 88.60 & 97.50 & 96.40 & 84.20 \\
\hline $\begin{array}{l}\text { Nayapara } \\
\text { RC }\end{array}$ & 88.31 & 89.83 & 84.69 & 84.53 \\
\hline
\end{tabular}

Table 10: Classification accuracies for each class. Object-based method using seg2 MLC classifier definition file.

\begin{tabular}{|l|c|c|}
\hline $\begin{array}{l}\text { Class } \\
\text { (Camp 1E,1W,17,19, } \\
\text { N RC) }\end{array}$ & $\begin{array}{l}\text { Mean } \\
\text { Producer } \\
\text { Accuracy } \\
\text { (Apr '18 } \\
\text { Jul '18 } \\
\text { Mar'19) }\end{array}$ & $\begin{array}{l}\text { Mean } \\
\text { User } \\
\text { Accuracy } \\
\text { (Apr '18 } \\
\text { Jul '18 } \\
\text { Mar'19) }\end{array}$ \\
\hline Light-tone roof & 70.86 & 87.75 \\
\hline Orange roof & 96.43 & 89.56 \\
\hline Green roof & 88.30 & 99.41 \\
\hline Brown roof & 38.87 & 47.64 \\
\hline Blue roof & 80.36 & 97.38 \\
\hline Dark-tone roof & 37.87 & 42.07 \\
\hline Yellow roof & 71.05 & 68.47 \\
\hline Water & 53.05 & 25.09 \\
\hline Dirt and mud & 52.72 & 39.66 \\
\hline Agriculture and grass & 1.62 & 4.57 \\
\hline Trees & 45.59 & 51.43 \\
\hline
\end{tabular}

\section{Discussion and conclusion}

This study demonstrates the potential scalable and transferable benefits of automated feature extraction methods, as the toolkit functioned as designed. A benefit of this method is the average processing time for each camp was 30 minutes compared to hours using manual extraction as demonstrated in other studies [8]. Comparison of automated and manual methods showed that as the area of interest doubled, so did the production time associated with manual extraction; however, only the computing time increased for automated methods [8]. Thus, once developed, automated methods can significantly save time associated with feature extraction. Furthermore, automated methods can be transferable, saving time associated with extraction updates [28]. This significantly improves the ability to monitor large and highly dynamic camps $[5,11]$. This study demonstrated the transferable benefits by combining automated feature extraction methods with a graphical user interface (GUI) for faster and interactive parameter adaptation and execution [8]. This combination enables non-technical users to leverage automated feature extraction processes, thus reducing the labor costs associated with feature extraction. However, the accuracy of automated tools using automated feature extraction methods rely on welldefined classifier definition files. This study highlights the difficulty of developing well-defined classifier definition files that are geographical and temporal transferable. As stated, the classifier definition files used in this study severely misclassified dirt and mud features as brown and gray roofs (Table 4,10 ), which resulted in an overly inflated roof area calculation, ultimately leading to severely overestimated populations (Table 8 ). 
On average, the RMSE and percent margin of errors for the two camps used to develop the classifier signatures files were significantly lower $(8,441$ and $15 \%)$ compared to the other three camps $(31,082$ and $214 \%$ ). This is likely the result of variations of features between each camp, density of populations (Table 6), and unknown post-image processes, thus altering the true spectral values and leading to inconsistent classifications (Table 9).

\subsection{Limitations of imagery-derived estimates} Despite the benefits of imagery-derived refugee and IDP camp population estimates when compared to field-based counts, this method is not perfect. The reliance on field-based information to calculate population estimates; the inability to differentiate building function and occupancy status; decreased accuracy in complex situations; spectral variance between sensors; geographical, seasonal, and building material effects on spectral signatures; and tree and cloud cover all limit the effectiveness and efficiency of imagery-derived population estimates. The accuracy of imagery-derived population estimates relies heavily on the accuracy of dwelling occupancy and density counts, often derived from field-base information. As stated, field-based information is inconsistent for numerous reasons, thus affecting the accuracy of imagery-derived estimates [5,9]. In this study, the discontinuation of covered area per person reporting limited the effectiveness of the tool to provide accurate population estimates. Additionally, unlike field-based surveys, imagery-derived information, especially through automated methods, is limited in its ability to identify building functions and occupancy status. This limitation leads to over-population estimates if all buildings are considered dwellings when calculating population estimates $[8,9,13]$. Underestimations can occur due to imagery-derived methods' decreased accuracy when extracting features in complex environments, such as high-density and multi-story dwellings [5, 8, 9, 13].

Automated image extraction methods are more sensitive to spectral variations, further decreasing their effectiveness and efficiency when those limitations are not properly addressed. Supervised automated image extraction methods rely on custommade rulesets derived from spectral signature of training areas from specific imagery and camp location, season, and building types. The spectral and spatial characteristics of the imagery used will affect effectiveness of automated image extraction methods [13]. Therefore, utilizing the same or similar image source is necessary to ensure consistent and accurate extraction. Additionally, as stated, the accuracy of feature extraction methods relies on well-defined classifier definition files. Enhanced spectral characteristics, such as bands outside the visible spectrum, can improve the definition of signature files. As demonstrated by [18], the use of multiple bands to create spectral indices can improve the effectiveness of automated feature extraction methods [18]. Thus, the limited spectral characteristics and possible inconsistencies in the spectral resolution of the imagery used in this study likely hampered the accuracy of the classifier definition files as demonstrated in their difficulty distinguishing similar colored but different features like brown roofs and dirt. Therefore, using imagery with greater spectral characteristics and resolution to develop the classifier definition file and classify would likely increase the accuracy of this toolkit, as demonstrated by [18]. The geographical location will also impact the spectral signatures used to identify camp features due to variations in the contrast between camp features and the surrounding environment and the use of different materials to build structures $[8,29]$. This is highlighted by the significant increase in margin of error and RMSE for test camps not used to develop the definition files despite being in close proximity with the camps used to develop the definition file. Additionally, seasonal variations can affect spectral signatures [30]. Lastly, tree and cloud cover can impede automated extraction efforts, thus leading to misclassification or the inability to conduct any extraction [17].

4.2 Future work: As stated, the effectiveness of population estimates derived from automated classification processes relies on the development of well-defined classifier definition files. Improving the classifier training methods, segmentation process, and incorporating additional information, such as spectral indices, as well as using higher quality imagery can improve the accuracy and transferability of classifier definition files. Although, this tool functioned as designed its accuracy was limited by the classifier definition file. Therefore, if humanitarian organizations dedicate the resources to develop a well-defined classifier definition file, they can use this toolkit to provide quick, up-to-date, consistent, and accurate population estimates, thus improving the ability to monitor and manage refugee and IDP camps. The toolkit also enables non-technical users to leverage automated feature extraction, thus lowering the number of technical users needed to derive population estimates from imagery.

Users of this toolkit can improve its accuracy by applying semi-automatic image analysis methods, as demonstrated by $[8,28,30]$. Semi-automatic image analysis combines automatic image analysis, as demonstrated in this study, with manual edits [8]. This 
requires users to manually inspect the output data and edit misclassified features. Although this will increase the processing time, it will improve the accuracy of the toolkit while decreasing processing time and costs associated with field-base and manual extraction population estimates [28].

Although it is difficult to provide accurate population estimates for a variety of reasons, the toolkit presented here is still useful for capturing

1. United Nations High Commissioner for Human Rights (UNHCR). Rohingya Refugee Emergency at a Glance.2019 March 4, 2019 Available from: https://unhcr.maps.arcgis.com/apps/Cascade/index.html?ap pid $=5 \mathrm{fdca} 0 \mathrm{f} 47 \mathrm{f} 1 \mathrm{a} 46498002 \mathrm{f} 39894 \mathrm{fcd} 26 \mathrm{f}$.

2. Ramadan A. Spatialising the refugee camp. Transactions of the Institute of British Geographers. 2012;38(1):65-77.

3. United Nations High Commissioner for Human Rights (UNHCR). Operational Review of UNHCR's Engagement in Situations of Internal Displacement2017 March 4, 2019 Available from: https://www.unhcr.org/protection/idps/5a02d6887/operatio nal-review-unhcrs-engagement-situations-internaldisplacement.html.

4. Joint IDP Profiling Service (JIPS). Stocktaking of Global Forced Displacement Data: Recognising the Value of Profiling IDP Situations. World Bank Report [Internet]. 2017 March 15, 2019. Available from: https://www.jips.org/jips-news/taking-stock-of-forceddisplacement-data/.

5. Checchi F, Stewart BT, Palmer JJ, Grundy C. Validity and feasibility of a satellite imagery-based method for rapid estimation of displaced populations. International journal of health geographics. 2013;12:4. doi: 10.1186/1476-072X-12-4. PubMed PMID: 23343099; PubMed Central PMCID: PMC3558435.

6. Ware A, Laoutides C. Myanmar's 'Rohingya' Conflict: Misconceptions and Complexity. . Asian Affairs. 2019;50(4).

7. REACH. Bangladesh. Where We Work. 2019 March 20, 2019. Available from: http://www.reachinitiative.org/where-we-work/past-operations/bangladesh. 8. Spröhnle K, Tiede D, Schoepfer E, Füreder P, Svanberg A, Rost T. Earth observation-based dwelling detection approaches in a highly complex refugee camp environment - A comparative study. . Remote Sensing. 2014;6(10):9277-97.

9. Kemper T, Jenerowicz M, Soille P, Pesaresi M. Enumeration of dwellings in Darfur Camps from GeoEye-1 satellite images using mathematical morphology. IEEE Journal of Selected Topics in Applied Earth Observations and Remote Sensing, . 2011;4(1):8-15.

10. International Organization for Migration (IOM), Norwegian Refugee Council (NRC), UN Refugee Agency(UNHCR). Camp Management Toolkit2015 March 20, 2019. Available from: https://www.sheltercluster.org/sites/default/files/docs/camp _management_toolkit_english_version.pdf. change. Thus, the methods presented here can be used for monitoring, managing, and planning of camps by providing an efficient way to identify changes taking place on the ground, which in turn can initiate fieldbased censuses and updating of information.

\section{References}

11. Füreder P, Lang S, Hagenlocher M, Tiede D, Wendt L, Rogenhofer E. Earth observation and GIS to support humanitarian operations in refugee/IDP camps. Geospatial Data and Geographical Information Science Proceedings of the ISCRAM 2015 Conference, Kristiansand, May 24 -27, 2015 [Internet]. 2015.

12. Duro DC, Franklin SE, Dube MG. A comparison of pixel-based and object-based image analysis with selected machine learning algorithms for the classification of agricultural landscapes using SPOT-5 HRG imagery. . Remote Sensing Environment. 2012;118:259-72.

13. Mossoux S, Kervyn M, Soulé H, Canters F. Mapping population distribution from high resolution remotely sensed imagery in a data poor setting. Remote Sensing. 2018;10(1).

14. Sarzin Z. Stocktaking of Global Force Displacement Data. World Bank Group. Fragility, Conflict and Violence Cross Cutting Solution Area. 2017 March 15, 2019 Available from: https://www.jips.org/uploads/2018/11/WorldBankStocktaking-Forced-Displacement-Data-2017.pdf. 15. Sun J, Yang J, Zhang C, Yun W, Qu J. Automatic remotely sensed image classification in a grid environment based on the maximum likelihood method. . Mathematical and Computer Modelling. 2016;58(3-4):573-81.

16. Campbell JB, Wynne RH. Introduction to Remote Sensing. Fifth Edition ed. New York: The Guilford Press. ; 2011.

17. Williams N, Quincey D, Stillwell J. Automatic Classification of Roof Objects from Aerial Imagery of Informal Settlements in Johannesburg. . Applied Spatial Analysis and Policy. 2015;9(2):269-81.

18. Kemper T, Jenerowicz M, Gueguen L, Poli D, Soille P. Monitoring changes in the Menik Farm IDP camps in Sri Lanka using multi-temporal very highresolution satellite data. . International Journal of Digital Earth. 2011;4:91-106.

19. United Nations High Commissioner for Human Rights (UNHCR). Bangladesh Refugee Emergency, Population factsheet, as of March 20192019 May 4, 2019 Available from: https://data2.unhcr.org/en/documents/download/68946.

20. United Nations Human Right Council and REACH. Rohingya Refugee Crisis, Camp Settlement and Protection Profiling, Cox's Bazar, Bangladesh, Round 3. The UN Refugee Agency [Internet]. 2018 March 4, 2019 Available from: https://data2.unhcr.org/en/documents/download/63821. 21. United Nations Human Right Council and REACH. Multi-Sector Needs Assessment, All Camps, Ukhiya/Teknaf, Cox's Bazar, Bangladesh, July 2018. The 
UN Refugee Agency [Internet]. 2018 May 4, 2019

Available from:

https://data2.unhcr.org/en/documents/download/66634.

22. International Organization for Migration (IOM).

IOM Bangladesh - Needs and Population Monitoring (NPM) Drone imagery and GIS package by camp (April 2018)2018. Available from: https://data.humdata.org/dataset/data-and-resources-bycamps.

23. International Organization for Migration (IOM). IOM Bangladesh - Needs and Population Monitoring (NPM) Drone imagery and GIS package by camp (July 2018)2018. Available from: https://data.humdata.org/dataset/iom-bangladesh-needsand-population-monitoring-npm-drone-imagery-and-gispackage-by-camp-july-2018.

24. International Organization for Migration (IOM). IOM Bangladesh - Needs and Population Monitoring (NPM) UAV imagery and GIS package by camp (March 2019)2019. Available from: https://data.humdata.org/dataset/iom-bangladesh-needsand-population-monitoring-npm-uav-imagery-and-gispackage-by-camp-march-2019.

25. ESRI. Understanding Segmentation and Classification.2016. Available from: http://desktop.arcgis.com/en/arcmap/10.3/tools/spatialanalyst-toolbox/understanding-segmentation-andclassification.htm.

26. Institute D.

27. Project TS. The Humanitarian Charter and Minimum Standards in Disaster Response. 2011:[402 p.]. Available from: http://www.unhcr.org/enus/partners/guides/3b9cc1144/humanitarian-charter-

minimum-standards-disaster-response-courtesy-

sphere.html.

28. Voigt S, Schoepfer E, Fourie C, Mager A. Towards semi-automated satellite mapping for humanitarian situational awareness. . IEEE Global Humanitarian Technology Conference 10-13 Oct 2014, San Jose, CA, USA [Internet]. 2014 March 22, 2019. Available from:

https://ieeexplore.ieee.org/document/6970315/authors\#auth ors.

29. Füreder $\mathrm{P}$, Tiede $\mathrm{D}$, Lüthje $\mathrm{F}$, Lang $\mathrm{S}$. Object-based dwelling extraction in refugee/IDP camps-challenges in an operational mode. . South-Eastern European Journal of Earth Observation and Geomatics. 2014;3(2S):539-44.

30. Tiede D, Krafft P, Füreder P, Lang S. Stratified template matching to support refugee camp analysis in OBIA workflows. . Remote Sensing. 2017;9(4):326. 